\title{
Infancias, genocidios, memorias. Representaciones discursivo-pedagógicas de procesos genocidas en el programa infantil La asombrosa excursión de Zamba (Pakapaka)
}

\author{
María Agustina Sabich \\ ... \\ E-mail: agustinasabich@hotmail.com
}

\begin{abstract}
Resumen
Como resultado de la implementación de la Ley de Servicios de Comunicación Audiovisual $\mathrm{N}^{\circ} 26.522$ sancionada en Argentina en 2009, Pakapaka (nombre de origen quechua que significa "escondite", juego de niños) se inscribe en un contexto sociopolítico de ampliación de derechos, conquistas culturales y democratización audiovisual, en la medida en que se define como el primer canal público y educativo destinado a las infancias. En este marco, el presente trabajo busca analizar -desde un enfoque sociosemiótico (Verón, 1993) y discursivo/pedagógico (Bernstein, 2005) - algunos de los procedimientos

discursivos presentes en un capítulo televisivo del programa infantil La asombrosa excursión de Zamba que refiere a las representaciones de genocidios históricos modernos. En particular, llevaremos adelante un análisis en producción, esto es, un análisis que puede describir la gramática de producción de un texto en torno de las cuales se puede inferir "un campo de efectos posibles de sentido" (Verón, 1993: 20). Asimismo, se contemplarán ciertos aportes conceptuales desarrollados en el campo artístico, fundamentalmente, aquellos especializados en el cruce entre imagen, arte y memoria.
\end{abstract}

Palabras clave: infancias; representaciones; discurso pedagógico; sociosemiótica; televisión.

\section{Childhood, genocides, memories. Discursive-pedagogical representations of genocidal processes in the children's program La asombrosa excursión de Zamba (Pakapaka)}

\begin{abstract}
As a result of the implementation of Audiovisual Communication Services Law $N^{\circ} 26.522$ sanctioned in Argentina in 2009, Pakapaka (Quechua origin name that means "hiding", children's play) is part of a socio-political context, which includes the exten-

sion of social rights, cultural achievements and audiovisual democratization, insofar as it is defined as the first public and educational channel for children. In this context, this paper aims to analyze - from a socioemiotic (Verón, 1993) and discursive / pedago-
\end{abstract}

Data de submissão: 2017-07-03. Data de aprovação: 2017-12-04.

A Revista Estudos em Comunicação é financiada por Fundos FEDER através do Programa Operacional Factores de Competitividade - COMPETE e por Fundos Nacionais através da FCT - Fundação para a Ciência e a Tecnologia no âmbito do projeto Comunicação, Filosofia e Humanidades (LabCom.IFP) UID/CCI/00661/2013.

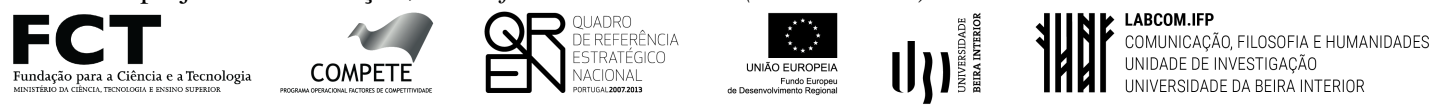


gical approach (Bernstein, 2005) - some of the discursive procedures present in a television chapter of the children's program La asombrosa excursión de Zamaba that refers to representations of modern historical genocides. In particular, we will carry out an analysis in production, that is, an analysis that can describe the production grammar of a text around which one can infer "a field of possible effects of meaning"(Verón, 1993, p. 20). Likewise, we will contemplate some conceptual contributions developed in the artistic field, mainly those specialized in the intersection between image, art and memory.

Keywords: childhood; representations; pedagogical discourse; sociosemiotic; television.

El problema es saber qué clase de humanos nos muestra la imagen y a qué clase de humanos está destinada, qué clase de mirada y de consideración es creada por esa ficción

Jacques Rancière

\section{Introducción: ¿Qué nos dejó un Estado inclusivo? Algunas referencias generales en torno a Pakapaka y La Asombrosa excursión de Zamba}

T A Ley argentina de Servicios de Comunicación Audiovisual (LSCA) $\mathrm{N}^{\circ} 26.522$ sancionada en L 2009 desarrolló un escenario mediático orientado a la producción de contenidos pluralizados en un contexto de ampliación de derechos y de democratización audiovisual. Pakapaka ${ }^{1}$ - nombre de origen quechua que significa "escondite" (juego de niños) - es uno de los resultados de su proceso de implementación. Al respecto, Murolo (2014, p. 212) señala que "la televisión no es un objeto ajeno a los acontecimientos políticos y sociales de un país. La televisión (...) determina y es sobredeterminada por el devenir cultural, los usos y apropiaciones, en definitiva, por los rituales que alrededor de ella se construyen".

Con sus avances y retrocesos, la LSCA establece un punto de quiebre a la hora de reemplazar la Ley de Radiodifusión Nacional $\mathrm{N}^{\circ} 22.285$, promulgada durante la última dictadura cívico-militar, en la medida en que establece un nuevo paradigma respecto de la comunicación, la ampliación de derechos, la desconcentración de medios audiovisuales, la multiplicación de señales, la apertura de licencias y la promoción de contenidos nacionales. En este proceso de transformación, en Argentina se impulsaron plataformas digitales dependientes del Ministerio de Educación de la Nación como el portal Educar, Conectáte y BACUA (Banco Audiovisual de Contenidos Universales Argentino) y canales públicos como DeporTv, INCAA TV, Canal Encuentro, Tecnópolis TV y ACUA Mayor.

Pakapaka se inscribe, además, en un marco social y político en el cual la relación entre la televisión y los niños está cambiando (Carli, 2006, 2002, 1999; Minzi, 2006; Duek, 2013). Esta transformación se debe, en parte, al hecho de que los "nuevos" programas representan a los niños asumiendo roles diferentes, manifestando actitudes activas y protagónicas que hacen que tomen cierta distancia de las directivas del mundo adulto. Hablamos de cierta distancia porque, obviamente, los programas de televisión destinados al público infantil mantienen contacto con las

1. Para visitar la página web del canal infantil ingresar a: www.pakapaka.gob.ar/ 
Infancias, genocidios, memorias. Representaciones discursivo-pedagógicas de procesos genocidas en el programa infantil La asombrosa excursión de Zamba (Pakapaka)

normativas que rigen el mundo de los adultos, a partir de la regularización de tiempos y espacios (Duek, 2013).

Entre los programas más vistos ${ }^{2}$ de Pakapaka merece la pena destacar La asombrosa excursión de Zamba, una serie animada producida por El perro en la luna y ambientada en el período que va de principios del siglo XIX a fines del siglo XX. Los sucesivos acontecimientos históricos son recreados por un niño inquieto y curioso ("Zamba") que interactúa con distintas figuras artísticas, políticas y sociales, entre las cuales podemos destacar, Faustino Sarmiento, José de San Martín, Juan Manuel de Rosas, Frida Kahlo, Karl Marx, Adam Smith, entre otros. El primer elemento distintivo de esta serie infantil es que el protagonista principal no es blanco, no vive en Buenos Aires y le gusta el chipá. Así, Zamba se construye como una figura que intentaría desplazar los marcos dominantes bajo los cuales la niñez se ha representado en tanto verdad única, centralizada e irrevocable, construida históricamente, desde un imaginario anglosajón.

\section{Marco teórico-metodológico: pensar las infancias desde la Teoría de los Discursos Sociales}

El estudio toma como principal marco metodológico la Teoría de los Discursos Sociales de Eliseo Verón (1993 [1988]), la cual es entendida como un "conjunto de hipótesis sobre los modos de funcionamiento de la semiosis social", o sea, tal como el autor la define, "la dimensión significante de los fenómenos sociales" (1993, p. 125). Para el teórico argentino, el estudio de la semiosis es "el estudio de los fenómenos sociales en tanto procesos de producción de sentido" (1993, p. 125), es decir, parte del principio de que dichos procesos se definen por un conjunto de condiciones socio-históricas, cuyas huellas se hacen presentes en los textos a través de marcas. Como señalamos anteriormente, en este trabajo llevaremos adelante un análisis en producción, esto es, un análisis que puede delimitar "un campo de efectos posibles de sentido" (1993, p. 20), o dicho de otra manera, que solo permite inferir el conjunto de reglas de lectura (gramáticas de producción) que se aplicaron a un discurso o paquete discursivo en un momento histórico-social determinado.

Otro de los aportes teóricos que será útil para nuestro análisis es el concepto de discurso pedagógico definido por Bernstein (2005, p. 139), entendido según el autor como "el conjunto de reglas y prácticas para la formación y transformación de la comunicación [didáctica]". El mismo se conforma a partir de la existencia de tres normativas: las reglas de distribución (que definen los sujetos destinatarios del discurso), las reglas de recontextualización (que corresponden a los procesos de transposición didáctica) y las reglas evaluativas (que regulan las relaciones sociales para la transmisión y la adquisición de materiales didácticos): "El discurso pedagógico no sería un repertorio de contenidos (conceptos, teorías o conjunto de enunciados) sino una gramática de producción de nuevos textos para su distribución, reproducción en el contexto de reproducción" (Bernstein \& Diaz, 1984, p. 32). Asimismo, serán necesarios para este artículo algunos aportes desarrollados en el campo artístico, más precisamente, nos encontramos interesados en los con-

2. Si bien Pakapaka no posee un sistema de medición de "rating" (en la medida en que no presenta financiamiento publicitario), los programas con mayor visualización pueden ser relevados a partir del nivel de circulación en las redes sociales. Entre ellos, podemos mencionar Minimalitos, Medialuna, aventuras en la selva, La asombrosa excursión de Zamba, Listo el Pollo, Desafiólogos, Caídos del Mapa y Vuelta por el Universo. 
ceptos de tropos universal y museificación (Huyssen, 2002), zona gris (Agamben, 2000), marcos (Butler, 2010), transmisión (Hassoun, 1996) y representación (Sontag, 2004).

La investigación intentará, por un lado, identificar los imaginarios sociales configurados en torno a procesos políticos represivos y, por otro lado, tratará de relevar algunas esquematizaciones relacionadas con las representaciones contemporáneas de la niñez, a partir de la reconstrucción de los procesos de investidura de sentido. Dichos procesos pueden evidenciarse -según Verón (1993) - en la superficie textual a través de la presencia de "marcas", las cuales nos permitirán reconstruir las "huellas" del discurso en cuestión. Para ello retomaremos los planteos de Peirce (1978) en los cuales se define la relación entre un signo y su objeto correspondiente a la segunda tricotomía. Su teoría postula que esta relación se pone en juego a través de lo que Verón denomina los "tres órdenes de funcionamiento significante", es decir, lo icónico (analogía), lo indicial (contigüidad) y lo simbólico (convencionalidad). En lo atinente al orden de lo icónico es posible relevar aquellas operaciones que estén basadas en una relación de semejanza y generen identificación de situaciones, personajes y/o escenarios. En lo que atañe al orden de lo indicial o de contacto pueden tenerse en cuenta tanto los modos en que los sujetos son representados como las funciones y los índices comentativos (Bettetini, 1984) y las marcas de todos los elementos que componen una imagen audiovisual (uso de planos, angulaciones, colores, caracterización de los espacios y personajes, recursos sonoros, entre otros). En lo referente al orden de lo simbólico, pueden tomarse en consideración aquellas operaciones que remitan a reglas y convenciones de género y estilos de época.

A su vez, la investigación contempla los tres niveles de construcción textual elaborados por Steimberg (1993), es decir, lo retórico, lo temático y lo enunciativo. Según destaca el autor, lo retórico no se corresponde con los elementos del ornamento del discurso, sino más bien, con todos los mecanismos de configuración de un texto, es decir, por ejemplo, organización de secuencias, tipo de música incidental empleada, utilización de tal o cual tipo de adjetivaciones. Por su parte, lo temático es definido como las situaciones y acciones que responden a esquemas de representabilidad, históricamente elaborados y relacionados, previos al texto. Los temas constituyen aquellos elementos estereotipados que dan cuenta de lo que semánticamente trata todo o gran parte de un discurso y que, por lo general, no se evidencian en la superficie del mismo, mientras que los motivos -que pueden estar presentes incluso en un número elevado- se manifiestan en la superficie textual, ocupando fragmentos específicos; estos pueden ser, tipos de personajes o de situaciones. Por último, Steimberg plantea que la dimensión enunciativa se define como "el efecto de sentido de los procesos de semiotización mediante los cuales se construye una situación comunicacional en un texto, a través de dispositivos que pueden ser o no de carácter lingüístico (...)". La definición de esa situación puede incluir "la relación entre un emisor y un receptor implícitos, no necesariamente personalizables" (1993, p. 44).

\section{Hipótesis y preguntas de investigación}

El análisis toma como referencia estudios previos (autor 2014 y 2015), en los cuales advertimos que las pantallas impulsadas por el Estado Nacional constituyen una herramienta fundamental para el desarrollo de los modelos educativos porque permiten el ingreso de otras variables forma- 
doras en el ámbito escolar, familiar y social. En este sentido, consideramos que el análisis de los productos audiovisuales destinados a las infancias debe contemplar no solo el estudio de las estrategias pedagógicas dinamizadas en ellos, sino también, la configuración significante que estructura su diseño. Esto implica analizar las posibilidades que abre la discursividad mediática -en tanto formadora de la subjetividad social- en pos de relevar las contradicciones y limitaciones que impone el dispositivo para evitar caer en "celebraciones tecnológicas" (Buckingham, 2008).

Siguiendo los planteos de Sontag (2004) podríamos señalar que la reconfiguración pedagógica de ciertos hechos traumáticos evidencia la problemática de la distancia entre la representación y lo representado. En este sentido, nos preguntamos ¿cómo son contados - desde un formato audiovisual- los genocidios históricos a los niños? A modo de hipótesis, consideramos que en el capítulo seleccionado se ponen en circulación dos mecanismos discursivos: el primero es aquél que denominaremos la ornamentación de lo monstruoso (que opera a través de la presencia de elementos técnicos y que puede visualizarse, por ejemplo, a partir de la construcción de escenarios caracterizados con colores llamativos, sonidos lúdicos y musicalizaciones festivas) y, el segundo mecanismo será conceptualizado como efecto de parodización, el cual opera a través del despliegue de estrategias paródicas que "ridiculizan" a los genocidas y "victimizan" a los pueblos perseguidos (dichos procedimiento se evidencian, principalmente, en el trazo "grotesco" y "desproporcionado" de los cuerpos y en sus gesticulaciones y en la articulación de éstas con los recursos sonoros empleados).

En este caso, consideramos que ambos mecanismos actúan de manera tal que restringen ciertos procesos reflexivos y críticos respecto del pasado reciente en la medida en que se busca construir la imagen de un niño-destinatario intolerante, es decir, un niño que no tiene la capacidad de conocer el horror sino es por una mediación frivolizante. Ante esta afirmación, nos interesa preguntarnos: ¿es posible diseñar un programa con contenido político destinado a un público infantil que aborde, por ejemplo, la temática de la desaparición y el genocidio de colectivos étnicos y que contemple paralelamente la protección y los derechos universales de la niñez? ¿Es posible que ese niño o niña vea un poco "más allá" de lo que se considera legítimo para la infancia?

Las preguntas específicas que guían la investigación son las siguientes: ¿En qué contexto histórico-político es pensada la niñez desde el programa infantil?, ¿Cuál es el rol que se le asigna a los procesos genocidas en dicho programa? ¿A través de qué procedimientos pedagógicos se construyen los hechos traumáticos?, ¿Desde qué marcos significantes se narra el hecho histórico? (Butler, 2010). ¿Qué modalidades de "transmisión" operan en esa reconfiguración? (Hassoun 1996), ¿Cuáles son los condicionamientos propios del dispositivo que restringen los modos de funcionamiento del discurso y que habilitan ciertas representaciones de las infancias contemporáneas? ¿Qué figuras de enunciadores y destinatarios se construyen?

\section{“Para qué sirve la memoria Ana Frank?": acerca del terror de "no mostrar” para cuidar}

El capítulo propuesto para el análisis se titula: "La asombrosa clase de Zamba sobre la memoria" y comienza en el ámbito escolar. Allí, la señorita Silvia les indica a los alumnos que la memoria es algo "muy importante" mientras señala en el pizarrón el año de promulgación de la Ley Universal de Derechos Humanos (1948). A partir de entonces, se ponen en funcionamiento 
una serie de recursos técnicos, como flashbacks, que llevan al personaje principal a recorrer distintos momentos históricos vinculados con procesos genocidas. Entre ellos, se destacan la matanza judía (que tiene como referente a Ana Frank), la armenia (cuyo protagonista es Ivahan Tekeyán), la indígena (que posiciona a Rigoberta Menchú como principal narradora) y finalmente, la matanza tutsi (en la cual Zamba entabla una conversación con Immaculé Ilibagiza).

Una de las principales preguntas que quisiéramos realizar es ¿Por qué se decide contar cuatro procesos genocidas -contextualizados en tiempos y espacios diferentes- en un solo video?, ¿En qué consiste dicha condensación? ¿Por qué se decide narrar, en primera instancia, el fenómeno de la matanza judía?, ¿Se trata de una elección arbitraria? Si retomamos los planteos de Huyssen (2002), podríamos advertir la presencia de cierta discursividad del holocausto devenida tropos universal como un prisma "a través del cual [es posible] percibir otros genocidios" (2002, p. 17). Dicha organización retórico-enunciativa, que ubica al holocausto primero y a las otras matanzas étnicas después, produce cierta visión sesgada de las experiencias históricas que, como advierte el autor, bloquea la reflexión sobre el desarrollo de procesos genocidas específicos. El problema reside entonces no solo en la manera en que se eligen contar ciertas experiencias pasadas, sino también, en el modo en que éstas son leídas e interpretadas. En definitiva, se trata de un problema de transmisión (Hassoun, 1996). Asimismo, es necesario preguntarse, ¿Acaso es posible homogeneizar la concepción del genocidio? ¿Se promueve el pensamiento crítico sobre el término o simplemente se recurre a la técnica del lenguaje audiovisual para hacer de los contenidos conceptuales algo "atractivo"? Posiblemente, como indica Sontag (2004, p. 134) "se le atribuye demasiado valor a la memoria y no a la reflexión".

Otra de las cuestiones que podríamos analizar es el despliegue de las distintas estrategias discursivo-pedagógicas utilizadas para "enseñar" el acontecimiento histórico en cuestión. En este sentido, podríamos advertir la presencia de tres operaciones de recontextualización recurrentes. Estas son: 1) el resumen biográfico, 2) el empleo de figuras icónicas como mapas, itinerarios y carteles y 3) explicaciones conceptuales realizadas por un enunciador "enciclopedista" y "testimonial". Cuando hablamos de "recontextualización" nos referimos a una modalidad propia del discurso pedagógico en la cual se despliegan estrategias lingüísticas y no lingüísticas que tienen como principal finalidad hacer que la explicación sea percibida como "clara" y "sencilla". Para ello, el discurso pedagógico se apropia de saberes científicos complejos y los "recontextualiza" según sus propios criterios de funcionamiento, a partir de mecanismos que implican tareas semejantes a la selección, la simplificación y la condensación (Bernstein, 2005).

Las modalidades relevadas funcionan a modo de "síntesis visual" para resumir la información que el enunciador quiere que sea incorporada y memorizada. La organización de dichas modalidades constituye un "enfoque esencialmente empírico" (Verón, 2004, p. 195), puesto que "a falta de una tipología del discurso teóricamente constituida, estamos obligados a partir de ciertos niveles -y en el interior de cada nivel, de ciertos desgloses- que aparecen en el seno mismo del sistema productivo de los discursos mediáticos" (2004, p. 195).

A continuación, realizaremos algunas descripciones de las estrategias discursivo-pedagógicas detectadas: 


\section{El resumen biográfico}

Los resúmenes biográficos suelen presentarse a modo de "flash informativo" y su principal función es la de detener el tiempo de la diégesis para generar una "etiqueta visual", en un recuadro que cubre toda la pantalla y que dura aproximadamente tres segundos (ver figuras 1 y 2). Dichos recuadros -que funcionan como marcos interpretativos (Butler, 2010) - brindan información de los actores más "representativos" del proceso genocida en cuestión, como por ejemplo, el nombre, el apellido y la procedencia étnica. En este segmento, el enunciador se posiciona en un lugar "didáctico" en la medida en que le confiere al destinatario los conceptos relevantes que debe memorizar, por lo que se evidenciaría una estrategia icónico-indicial de simplificación (Bernstein, 2005).

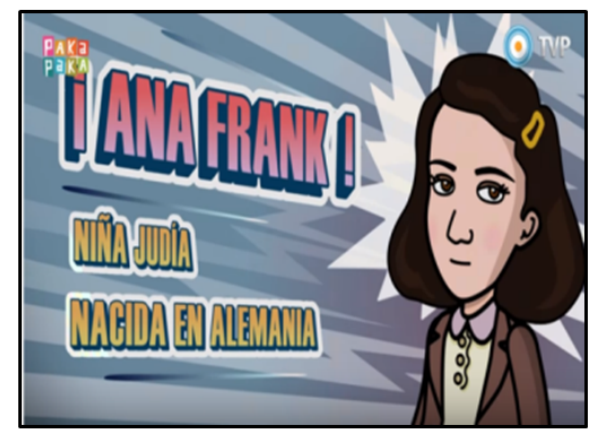

Figura 1

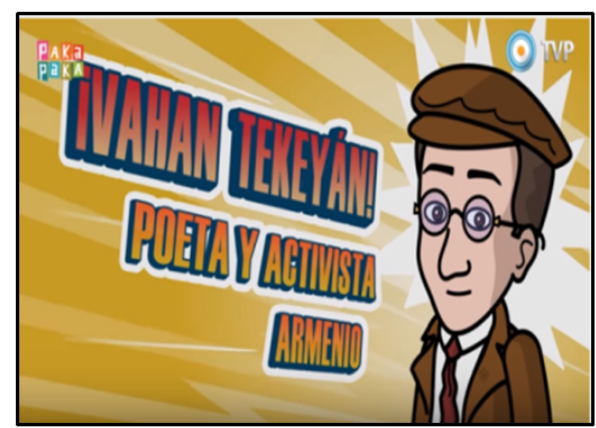

Figura 2

En lo que respecta a la dimensión icónica, resulta significativa la presencia de un estilo artístico tradicional que implica el trazado a mano, junto con el despliegue de sujetos caricaturizados de cabezas grandes, cuerpos pequeños y gestos afligidos. Se trata de una estrategia discursiva orientada 
a lo paródico ${ }^{3}$ que buscaría reconstruir los procesos históricos a partir de la vida de un personaje popular que sirva como "puente" para hablar del contexto político, con una modalidad que oscila entre lo humorístico y lo serio. En este último caso, lo serio se reconstruye indicialmente, a partir del rostro "entristecido" de las víctimas, así como en los colores apagados de sus vestimentas y en el tono silencioso de sus palabras, los cuales -desde un plano simbólico-intentarían representar "encierro" o "persecución". Lo humorístico, en cambio, irrumpe no solo con la musicalización introductoria de fondo (propia del flash informativo), sino también con el volumen y la entonación de la voz del enunciador, que con un estilo "grave" anticipa conceptos centrales a "recordar" y vehiculiza un sentido lúdico para lograr que la explicación sea incorporada rápidamente por el destinatario. Como señala Rocha-Alonso (2008, p. 11) siguiendo los planteos de Chion, "la música acentúa, crea climas y anuncia lo que ha de venir (...)". Aquí, resulta interesante pensar que esta modalidad discursiva no aplica para todos los personajes sino únicamente para las "víctimas", en un intento por darle "voz" a los excluidos y quitarle entidad a los persecutores, creando cierta distancia con la presencia corporal de estos últimos.

\section{El empleo de figuras icónicas como mapas, itinerarios y carteles}

La segunda modalidad que suele ser utilizada para la enseñanza del acontecimiento histórico es aquella que se vincula con el despliegue de mapas que sirven para generar cierta contextualización territorial del proceso político narrado. En este segmento, la imagen del enunciador se fragmenta y, en lugar de mostrarse como una figura orientada a lo "didáctico", pasa a constituirse como un sujeto que relata un episodio traumático en pos de producir cierta "conmoción". En términos de Barthes (1990, p. 123), "conmover (animos impellere) es pensar el mensaje probatorio no en sí mismo sino según su destino, el humor de quién debe recibirlo, en movilizar pruebas subjetivas, morales". A diferencia del apartado anterior, la estrategia retórico-enunciativa, en este caso, buscaría reafirmar un mayor efecto de verosimilitud del pasado reciente para interpelar al destinatario desde un lugar no solo conceptual sino también experiencial, contribuyendo de esta manera, en la representación de un enunciador "victimizado".

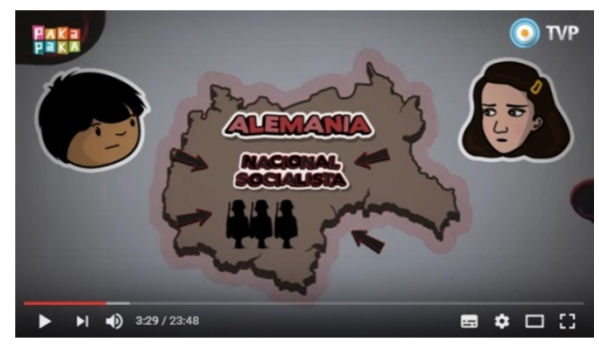

Figura 3

3. En términos de Hutcheon (1984, p. 178-179), podríamos definir a la parodia como "una síntesis bitextual que funciona siempre de manera paradójica, es decir con el fin de marcar una transgresión (...), la parodia representa una señal de diferencia por medio de una superposición de contextos (...)". 


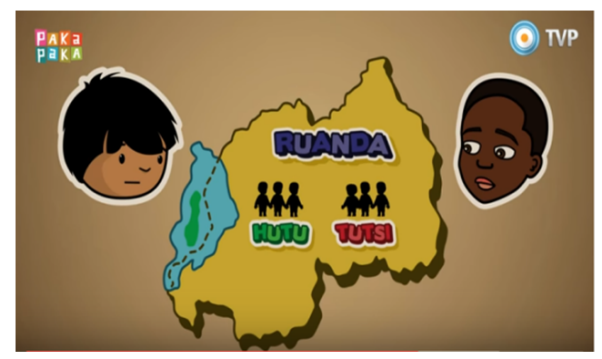

Figura 4

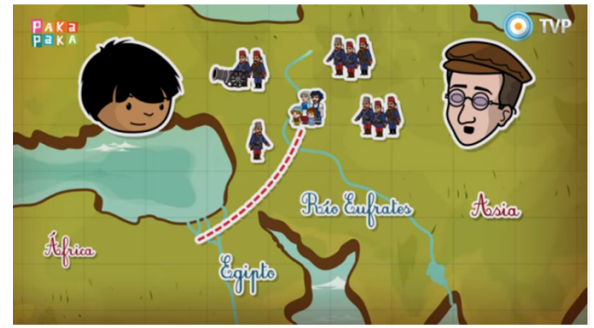

Figura 5

Como puede verse en las imágenes presentadas (figuras 3, 4 y 5), las caras de los protagonistas llaman compulsivamente nuestra atención, en principio porque se encuentran lo suficientemente despegadas del fondo -el cual parecería cumplir la función de "pizarrón", tecnología pionera de la educación moderna-, pero también porque aquellas se exhiben como rostros sin cuerpo, que lejos de expresarse como entidades individuales, representan una idea de comunidad, es decir, se constituyen como portavoces "legítimos" del pueblo perseguido: "en todos estos casos, el rostro no actúa como individual, la individuación es el resultado de la necesidad de que haya rostro" (Deleuze y Guattari, 2002, p. 180). Por tal motivo, la estrategia discursivo-pedagógica es la de condensación (Bernstein (2005), en la medida en que la población perseguida se "rostrifica" en una única figura, generando de esta manera, cierto efecto de verdad pero también de opacidad (Didi-Huberman, 2004). Aquí, vale la pena preguntarse por el lugar del sujeto de la enunciación y la restricción que implica darle "voz" a un solo representante del acontecimiento histórico-político, puesto que parecería construirse cierta discursividad monódica y autorreferencial. ¿Acaso se trata de una economía propia del discurso pedagógico que busca reducir la información para volverla fácilmente transmitible? ¿O bien se trata, siguiendo los planteos de Huyssen, de un efecto de museificación en el cual la memoria se presenta como un trofeo a ser reivindicado y no como una compleja mixtura de experiencias, sensibilidades y realidades? ¿Quién define qué figura es un símbolo del proceso político y quién no? ¿Por qué lo "real” es representado en términos unívocos? ¿Por qué el niño-destinatario no puede conocer más? 


\section{Explicaciones conceptuales realizadas por un enunciador "enciclopedista" y "testimonial"}

Una problemática común en el discurso pedagógico es aquella que se vincula con la explicitación de la voz ajena. Como hemos mencionado anteriormente, producto de los procesos de transposición didáctica, el discurso pedagógico tiende a recontextualizar los saberes con el objetivo de que los mismos sean incorporados fácilmente por los destinatarios. Uno de los mecanismos tradicionales que suele emplearse para lograr que la explicación sea percibida como clara y sencilla es la eliminación de las condiciones de producción (Hyland, 2000), generando de esta manera, un efecto de transparencia y de objetividad (Chevallard, 1991). Sin embargo, en la actualidad dichos procedimientos se han flexibilizado ${ }^{4}$ y existe un cierto consenso en considerar a los textos pedagógicos (lingüísticos y no lingüísticos) como permeables a la incorporación de múltiples voces, o en términos de Bajtín (1984), abiertos al desarrollo de su carácter polifónico. Por tal motivo, cabe preguntarse ¿Quiénes son los enunciadores que se construyen como autoridades en la transmisión del saber? En este segmento, hemos advertido que el enunciador se desdobla en dos clases de figuras: por un lado, éste aporta conocimientos desde un plano "enciclopedista", orientado al desarrollo de definiciones conceptuales, representado en la figura del niño "que lo sabe todo" (ver figura 6), y por otro lado, brinda información desde un lugar "testimonial" (encarnado en las voces de Ana Frank, Ivahan Tekeyán, Rigoberta Menchú e Immaculé Ilibagiza).

En el primero de los casos, el enunciador se posiciona en un lugar más bien asimétrico -a pesar de que esta asimetría aparece "disimulada" en la medida en que el sujeto que enseña es un niño y no un adulto- y su principal tarea reside en fijar definiciones conceptuales, como si se tratara de un diccionario audiovisual: "no estamos lejos del Éufrates, uno de los ríos más importantes de Asia occidental"; "los tutsis y los hutus son dos pueblos que durante más de un siglo se pelearon para dirigir este país"; "un genocidio es un plan organizado para perseguir y acabar con una población por sus características religiosas, étnicas, raciales o nacionales"; "una nación se define por su tierra, pero también por su lengua, su cultura y su historia" [enunciados del niño que "lo sabe todo"]. De esta manera, el enunciador le indica al destinatario inexperto, cuál es la información relevante que debe memorizar.

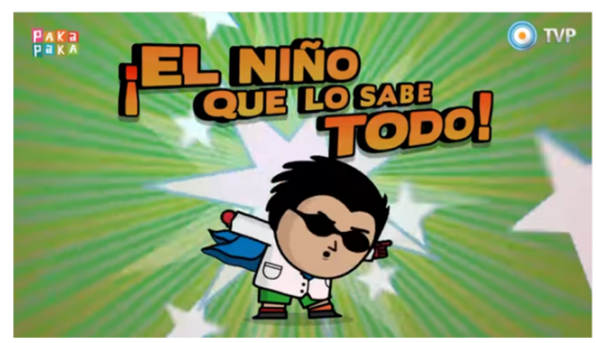

Figura 6

4. La flexibilización de estos mecanismos se debe, en parte, a las reformas propuesta por la Ley Federal de Educación (1993), la Ley de Educación Nacional (2006) y por las tendencias del diseño editorial y multimedial que incorporaron estrategias "novedosas" en la construcción discursiva de los materiales didácticos con la finalidad de atraer la atención de los destinatarios. 
Siguiendo los planteos de Orlandi (2003), la configuración del discurso pedagógico supone, en primera y última instancia, el establecimiento de un diálogo asimétrico: por un lado, el enunciador es la figura que posee el saber, mientras que la figura del destinatario no lo tiene y, por lo tanto, debe adquirirlo. Al respecto, la teórica brasileña destaca que se trata de un discurso autoritario, en el que intervienen relaciones de poder -dado que el enunciatario no puede "responder" las afirmaciones que el enunciador realiza-, además de que subyace la idea de que hay un único agente portador de la voz legitima. En este sentido, La asombrosa excursión de Zamba parecería reponer cierta concepción tradicional de la educación, a pesar de la intención por incorporar recursos "novedosos", en este caso, para la enseñanza de contenidos históricos.

En el segundo de los casos, el enunciador se posiciona en un lugar más bien "testimonial", en el cual los cuatro representantes de los diferentes procesos genocidas se presentan como los únicos narradores legítimos para referirse al acontecimiento histórico-político. Esta estrategia, que ubica el testimonio de las víctimas en primera instancia, y que posiciona a los victimarios en segundo plano, nos lleva a retomar la hipótesis planteada al comienzo de este artículo y que denominamos el efecto de parodización, es decir, una suerte de procedimiento discursivo que tiende a la "ridiculización" de los genocidas y a la "victimización" de los pueblos perseguidos. El primero de ellos puede visualizarse en las imágenes presentadas a continuación (ver figuras 7, 8 y 9):

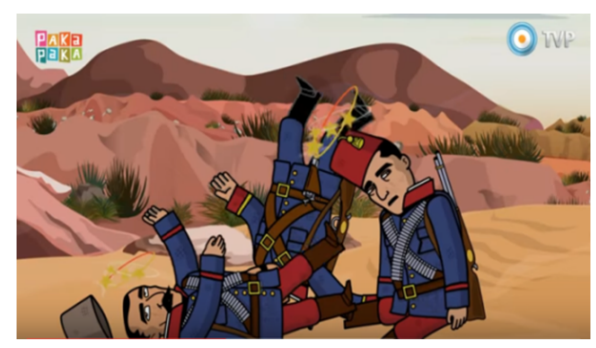

Figura 7

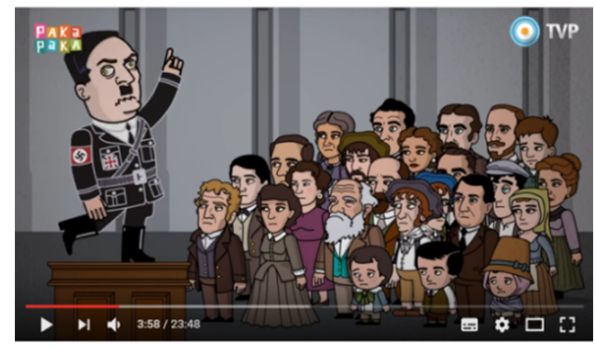

Figura 8 


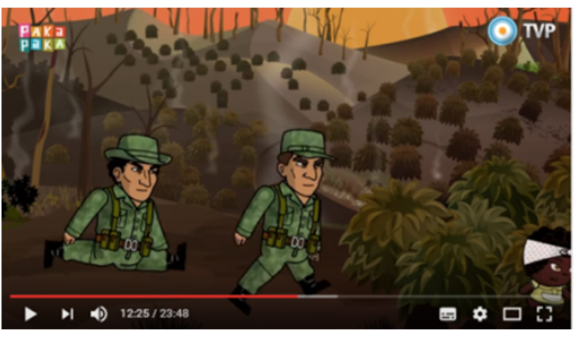

Figura 9

Las impresiones de pantalla capturadas podrían ejemplificar la idea de la construcción del enemigo como sujeto "irracional" o "inofensivo", principalmente, porque la caracterización de los cuerpos y de los rostros aparece de manera "burlona". Cabe destacar que esta visión sobre los genocidios y sus ejecutantes ha sido cuestionada por los planteos de Adorno y Horkheimer (1969 [1994]) respecto de la racionalidad de la ilustración, entendida no como un acontecimiento sin lógica propia -eso que Arendt denominó "la banalidad del mal" (1999 [1963]) -, sino como una estructura de exterminio organizada, pensada y planificada.

Si bien desde el dispositivo lingüístico existen claras referencias respecto del opresor como principal responsable de los genocidios ${ }^{5}$, desde el dispositivo técnico, por el contrario, la figura de éste tiende a generar cierto efecto cómico, mostrándose desresponsabilizado de todo acto racional de exterminio. Esto puede verificarse no solo en la forma en que se lo muestra (ojos desviados, piernas elásticas, cuerpos que se chocan entre sí), sino también en el tiempo acotado que se le asigna en el relato. Posiblemente, esta estrategia se deba a la necesidad (política) de otorgarle primacía a las voces de las víctimas, en detrimento de las voces de los victimarios, a quiénes se les adjudica un lugar desdibujado, casi desvinculado del proceso histórico, que en muchas ocasiones no solo se exhibe agraciado, sino también ensombrecido o bien endemoniado (ver figuras 10, 11 y 12):

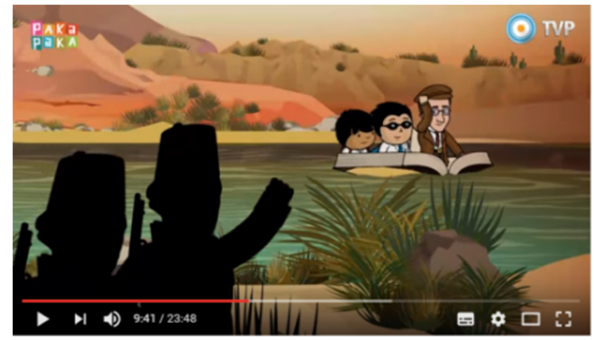

Figura 10

5. Dichas referencias pueden verificarse en las explicaciones que brindan las "víctimas", en las preguntas que realiza el protagonista y en las intervenciones que generalmente realiza el "niño que lo sabe todo". 


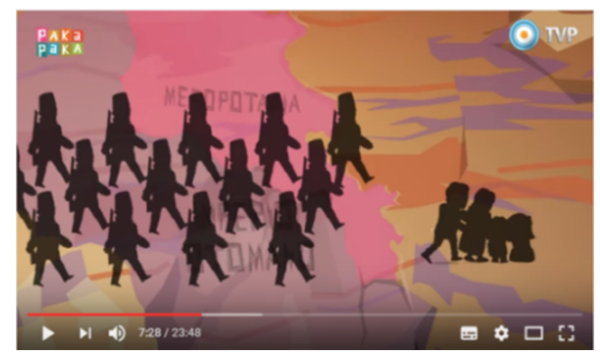

Figura 11

Figura 12

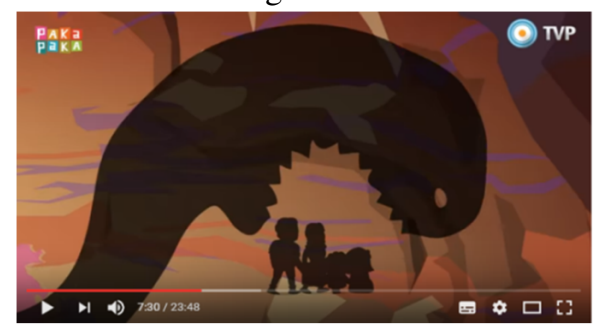

El otro, el enemigo, el opresor no es humano sino monstruoso; no tiene cuerpo, ni sexo, ni competencia, ni voz; no actúa por convicción lógica sino por voluntad maliciosa, no posee conciencia racional sino una auténtica y natural voracidad por perpetrar. No es el resultado de un proyecto político moderno de exterminio, sino una sombra fantasmagórica que acecha a un pueblo que no lucha y que solo puede escapar. Esta última idea nos conduce al segundo mecanismo discursivo que hemos advertido a modo de hipótesis y que se relaciona con la caracterización de los pueblos perseguidos en términos de victimización. Como puede observarse en las imágenes presentadas a continuación (13 y 14), la representación de éstos se vincula con una fuerte idea de "persecución".

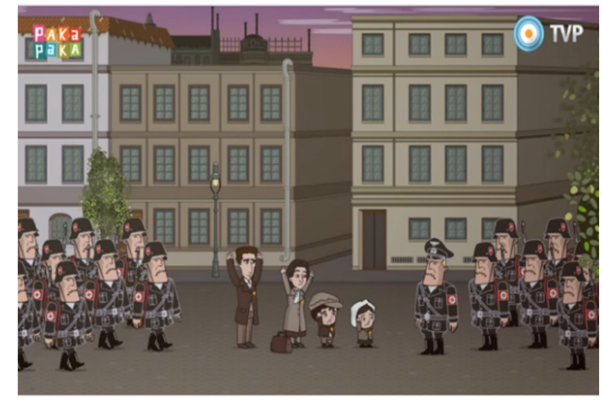

Figura 13 


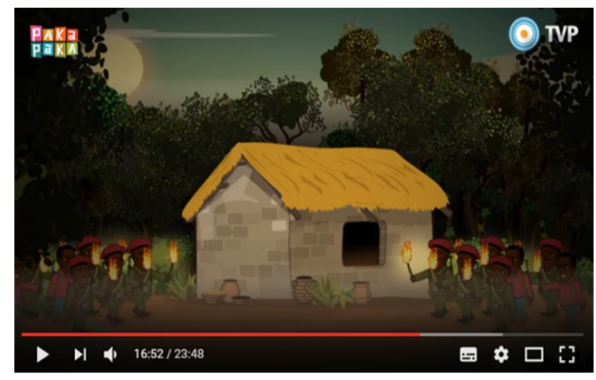

Figura 14

Desde un plano icónico-indicial, generalmente, la figura del oprimido aparece "encerrada" o "arrinconada" por los ejércitos genocidas -en ocasiones también se lo muestra huyendo-y en muy pocas oportunidades se los muestra luchando o enfrentando dicha persecución. ¿Qué hay entonces de la lucha armada, de las resistencias, de los contra-ataques políticos? La estrategia retóricoenunciativa que tiende a la construcción binaria de "persecutores/perseguidos", "buenos/malos", "opresores/oprimidos" restringe los procesos políticos de exterminio volviéndolos homogéneos y limita la conceptualización del genocidio en tanto "zona gris" (Agamben, 2000, p. 21): "una gris e incesante alquimia en la que el bien y el mal, y junto a ellos, todos los metales de la ética tradicional alcanzan su punto de fusión".

\section{Apreciaciones finales}

A lo largo de este artículo, hemos intentado describir algunos de los procedimientos discursivo-pedagógicos puestos en juego en un programa de La asombrosa excursión de Zamba orientado a la representación de genocidios históricos modernos (la matanza judía, armenia, indígena y tutsi). En particular, nos interesamos por reconstruir las estrategias discursivas utilizadas para problematizar los mecanismos mediante los cuales los acontecimientos históricos son contados a los niños. De esta manera, se han detectado tres procedimientos principales de recontextualización: en primer lugar, el resumen biográfico, en segundo lugar, el empleo de figuras icónicas como mapas, itinerarios y carteles, y en tercer lugar, explicaciones conceptuales realizadas por un enunciador "enciclopedista" y "testimonial".

Con respecto al resumen biográfico, detectamos que el posicionamiento del enunciador se orienta hacia un lugar "didáctico", por lo que también se ha verificado la presencia de una estrategia icónico-indicial de simplificación (Bernstein, 2005). Esto puede observarse en el despliegue de lo que denominamos "etiquetas visuales" que sintetizan informaciones relacionadas con las figuras de los colectivos étnicos perseguidos. A su vez, otra de la estrategia discursiva predominante es la paródica, en la medida en que se tiende a reconstruir la imagen del "perseguido" en términos de victimización, con una modalidad de significación que oscila entre lo serio (a partir de la figuración del rostro entristecido, el despliegue de colores opacos y el tono silencioso de sus palabras) y lo humorístico (a través de la irrupción de los flashes informativos y la entonación del 
presentador). Posiblemente, esta modalidad contradictoria se desarrolle con la finalidad de causar la menor angustia posible en el niño-destinatario y para que asimile de forma rápida los conceptos enseñados. Consideramos que al priorizar la voz de las "víctimas" y excluir la de los victimarios, se tiende a generar una lectura sesgada de la historia reciente, además de que no se presentan aportes conceptuales significativos (o bien interrogantes críticos) que no puedan ser explorados en otros textos pedagógicos tradicionales como manuales, diccionarios o enciclopedias. El enunciador apela, entonces, a que el destinatario "memorice" conceptos y no que reflexione o que se sienta conmovido por las imágenes.

En relación con el segundo mecanismo de recontextualización, es decir, el empleo de figuras icónicas como mapas, itinerarios y carteles, evidenciamos que desde un plano icónico-indicial la imagen del enunciador se repliega hacia lo "testimonial", a partir del relato de un episodio traumático que interpela al destinatario desde un lugar de conmoción. En este caso, la estrategia discursivo-pedagógica predominante es la de "condensación", en la medida en que la población perseguida se "rostrifica" en una sola figura, construyendo de esta manera, cierta visión unívoca, monódica y autorreferencial del proceso genocida tratado.

Con respecto al tercer mecanismo de recontextualización, este es, el de las explicaciones conceptuales realizadas por un enunciador "enciclopedista" y "testimonial", notamos que éste se desdobla, por un lado, para brindar definiciones conceptuales de "diccionario" (representado en la figura del niño que lo sabe todo), y por otro lado, para ofrecer información desde un lugar testimonial (encarnado en las voces de Ana Frank, Ivahan Tekeyán, Rigoberta Menchú e Immaculé Ilibagiza). En este apartado, el enunciador entabla un diálogo asimétrico con el destinatario, en la medida en que su principal tarea es la de "fijar" definiciones conceptuales, con la finalidad de indicarle los elementos importantes que debe memorizar. Aquí evidenciamos cierto sobredimensionamiento de la alfabetización tradicional para la enseñanza de contenidos históricos, independientemente de que se recurra al lenguaje audiovisual para hacer de dichos contenidos algo "atractivo".

Por otro lado, el enunciador también se posiciona en un lugar testimonial, el cual si bien parecería aportar cierta visión "democrática" del hecho traumático, contribuye en la "ridiculización" de los genocidas y en la "victimización" de los pueblos perseguidos. Esta estrategia puede evidenciarse, en el primer caso, mediante la impronta "burlesca" de los cuerpos, que desresponsabiliza al opresor de todo acto racional de exterminio, y en el segundo de los casos, mediante cierta actitud pasiva de los colectivos étnicos, por lo que generalmente se los exhibe escapando y pocas veces luchando.

En términos generales, la estrategia retórico-enunciativa que predominaría en el programa infantil tiende a la construcción de binarismos, mediante los cuales los procesos de exterminio -lejos de ser representados como prácticas complejas, multiformes y dinámicas- son entendidos en términos homogéneos. Es por esta razón que el discurso pedagógico "ornamenta" la crudeza del hecho traumático fundamentalmente desde lo técnico, para hacer de la narración audiovisual algo "tolerante" -orientada al goce estético- en pos de proteger al niño de cualquier sensación "sufriente" o "angustiante", puesto que en ninguno de estos casos, el niño podrá aprender lo que "debe" ser aprendido. 


\section{Bibliografía}

Agamben, G. (2000). Lo que queda de Auschwitz. El archivo y el testigo. Homo sacer III. Valencia: Pre-textos.

Arendt, H. (1999 [1963]). Eichmann en Jerusalén. Un estudio sobre la banalidad del mal. Barcelona: Lumen.

Bajtín, M. (1998 [1979]). Estética de la creación verbal. México D.F.: Siglo XXI.

Barthes, R. (1990 [1985]). La aventura semiológica. Barcelona: Paidós.

Bernstein, B. \& Diaz, M. (1984). Towards a theory of pedagogic discourse. CORE, 8 (3).

Bernstein, B. (2005). Clases, códigos y control II. Hacia una teoría de las transmisiones educativas. Madrid: Akal.

Bettetini, G. (1984). Tiempo de la expresión cinematográfica. México D.F.: Fondo de Cultura Económica (FCE).

Buckingham, D. (2008). Más allá de la tecnología. Aprendizaje infantil en la era de la cultura digital. Buenos Aires: Manantial.

Butler, J. (2010). Marcos de guerra. Las vidas lloradas. Buenos Aires: Paidós.

Carli, S. (1999). La infancia como construcción social. De la familia a la escuela. Infancia, socialización y subjetividad. Buenos Aires: Santillana.

Carli, S. (2002). Niñez, pedagogía y política. Transformaciones de los discursos acerca de la infancia en la historia de la educación argentina entre 1880 y 1955. Buenos Aires: Miño y Dávila.

Carli, S. (2006). La cuestión de la infancia. Entre la escuela, la calle y el shopping. Buenos Aires: Paidós.

Chevallard, Y. (1991). La transposición didáctica. Del saber sabio al saber enseñado. Buenos Aires: FCE.

Deleuze, G. \& Guattari, F. (2002). Mil mesetas. Valencia: Pre-textos.

Didi-Huberman, G. (2004). Imágenes pese a todo. Memoria visual del Holocausto. Barcelona: Paidós.

Duek, C. (2013). Infancias entre pantallas. Las nuevas tecnologías y los chicos. Buenos Aires: Capital Intelectual.

Hassoun, J. (1996). Los contrabandistas de la memoria. Buenos Aires: Ediciones de la Flor.

Horkheimer, M. \& Adorno, T. (1994 [1994]). Dialéctica de la ilustración. Fragmentos filosóficos. Madrid: Trotta.

Hutcheon, L. (1984). A theory of parody: the teachings of Twentieth-century art forms. University of Illinois: Press.

Huyssen, A. (2002). En busca del futuro perdido: cultura y memoria en tiempos de globalización. México D.F.: Fondo de Cultura Económica. 
Infancias, genocidios, memorias. Representaciones discursivo-pedagógicas de procesos genocidas en el programa infantil La asombrosa excursión de Zamba (Pakapaka)

Hyland, K. (2000). Disciplinary discourses, social Internactions in academic writing. London: Longman.

Ley n ${ }^{\circ}$ 26.522. Ley de Servicios de Comunicación Audiovisual. 2009. Congreso de la Nación Argentina, Argentina. Disponible: http://bamuac.unc.edu.ar/sites/bamuac.unc.edu.ar/files/servi cios-de-comunicacion-audiovisual-ley-26522.pdf

Ley n ${ }^{\circ}$ 24.195. Ley de Educación Federal. 1993. Congreso de la Nación Argentina, Argentina. Disponible: www.educ.ar/recursos/90044/ley-federal-de-educacion-n-24195-de-la-republica -argentina

Ley no 26.206. Ley de Educación Nacional. 2006. Congreso de la Nación Argentina, Argentina. Disponible: www.me.gov.ar/doc_pdf/ley_de_educ_nac.pdf

Minzi, V. (2006). Los chicos según la publicidad. Representaciones de infancia en el discurso del mercado de productos para niños. La cuestión de la infancia. Entre la escuela, la calle y el shopping. Buenos Aires: Paidós.

Murolo, N. (2014). Nuevas pantallas para la televisión pública argentina. La televisión en la década kirchnerista. Democracia audiovisual y batalla cultural (pp. 209-222). Provincia de Buenos Aires: Universidad Nacional de Quilmes.

Orlandi, E. (2009 [2003]). A Linguagem e seu funcionamento. As formas do discurso. Campinas: Pontes.

Peirce, C. S. (1978). Fragmentos de la ciencia de la semiótica. Buenos Aires: Nueva Visión.

Rancière, J. (2010). El espectador emancipado. Buenos Aires: Manantial.

Rocha-Alonso, A. (2008). De lo indicial, lo icónico y lo simbólico en las manifestaciones del sentido. Material de cátedra de la materia Semiótica de los Medios, Titular Prof. María Rosa del Coto, Carrera de Ciencias de la Comunicación, Facultad de Ciencias Sociales, Universidad de Buenos Aires.

Sabich, M. A. (2014). De los libros de texto a los portales educativos: un análisis sociosemiótico sobre los procedimientos discursivos en Introducción a la Comunicación y Educar. Tesina no publicada de la Licenciatura en Ciencias de la Comunicación, Facultad de Ciencias Sociales, Universidad de Buenos Aires.

Sabich, M. A. (2015). El discurso pedagógico en tiempos de Internet: aproximaciones sociosemióticas al estudio de los portales educativos. Tonos Digital, (29): 1-27. Murcia: Facultad de Letras, Universidad de Murcia. Disponible: www.tonosdigital.com/ojs/index.php/tonos/article/ viewFile/1302/778

Sontag, S. (2004). Ante el dolor de los demás. México D.F.: Alfaguara.

Steimberg, O. (1993). Semiótica de los medios masivos. El pasaje a los medios de los géneros populares. Buenos Aires: Atuel.

Verón, E. (1993 [1988]). La semiosis social. Fragmentos de una teoría de la discursividad. Barcelona: Gedisa.

Verón, E. (2004). Fragmentos de un tejido. Barcelona: Gedisa. 


\section{Agradecimientos}

El artículo se inscribe en el proyecto de investigación UBACyT (2014-2017) con sede en la Facultad de Ciencias Sociales de la Universidad de Buenos Aires (Argentina) y cuenta con el financiamiento de la Secretaría de Ciencia y Técnica de la misma institución. 